\title{
CANADIAN PRESSURE OBSERVATIONS AND CIRCULATION VARIABILITY: LINKS TO AIR TEMPERATURE
}

\author{
VICTORIA C. SLONOSKY ${ }^{\dagger}$ and EDWARD GRAHAM* \\ Climate Monitoring and Data Interpretation Division, Climate Research Branch, Meteorological Service of Canada, Environment \\ Canada, 4905 Dufferin St, Downsview, Ontario M3H 5T4, Canada
}

Received 14 May 2004

Revised 23 December 2004

Accepted 1 March 2005

\begin{abstract}
A set of 71 station series of surface pressure from Canada and Greenland have been examined for quality control and homogeneity. These records range in length from 50 to 130 years. The object of this exercise was to investigate stationbased surface pressure series and atmospheric circulation on a decadal time scale, and to examine the effects of the atmospheric circulation on climate. The data considered here are monthly means.

Several major inhomogeneities were discovered during the course of this exercise, the most serious of which relates to a Canadian-wide change in reporting practice which took place in 1977. This type of inhomogeneity is almost impossible to uncover using conventional homogenization techniques based upon reference series. The final homogenized series show appreciable differences in regional trends of atmospheric pressure compared with the unhomogenized series, particularly in southern Canada.

Empirical orthogonal function (EOF) analyses on the station series revealed three main modes of circulation over Canada and Greenland; these patterns were compared with results from the UK Hadley Centre's gridded pressure dataset. There are appreciable differences between the leading EOF modes of the two datasets, which may be due to an artificially enhanced number of degrees of freedom in the gridded dataset. Trends in atmospheric pressure were also calculated; these suggest an intensification of zonal flow during winter over the period 1950-98, but these variations appear to be much less pronounced and not statistically significant when considered over the whole of the 20th century.

The new station database was also compared with a gridded surface temperature dataset. There are strong correlations between the various circulation indices and temperature anomalies. Some of the trends of temperature in Canada during the period 1950-98 can be attributed to these changes of atmospheric circulation. The regional atmospheric circulation indices described here are shown to have considerable influence on the surface temperature variability and trends for all seasons of the year.
\end{abstract}

KEY WORDS: Canada; Greenland; station pressure; observations; atmospheric pressure; homogenization; atmospheric circulation; empirical orthogonal functions; temperature

\section{INTRODUCTION}

Climate change is one of the most important issues of our times, with anthropogenic climate change having potentially high socio-economic impacts. The atmospheric circulation plays a fundamental role in redistributing heat and moisture and, as such, is critical to our understanding of climate variability and climatic change.

The atmospheric circulation is described through changes in atmospheric pressure. Atmospheric pressure at the Earth's surface has been measured since the invention of the barometer by Evangelista Torricelli (1608-47) in 1644 (Middleton, 1964). In the past 50 years, upper air observations have led to a more complete understanding of the atmospheric circulation dynamics in the free troposphere and stratosphere.

\footnotetext{
* Correspondence to: Edward Graham, Department of Geosciences, University of Fribourg, Chemin de Musée 4, Pérolles, Fribourg, CH-1700 Switzerland; e-mail: edward.graham@unifr.ch

${ }^{\dagger}$ Present address: Ouranos Consortium for Regional Climate Change and Adaptation, Department of Atmospheric and Oceanic Sciences, McGill University, 550 Sherbrooke St W, Montréal, Québec H3A 1B9, Canada.
} 
However, for the study of decadal- to century-scale atmospheric circulation dynamics, the only data available are those of surface pressure. Many observations of surface pressure exist, but most are still in paper form, and need to be collected, digitized, quality controlled and homogenized before they can be effectively used for analysis of decadal-scale circulation variability. The homogenization procedure is especially important, as non-climatic changes, such as site relocations, instrument replacement, or changes in the observation practice (including changes in the time of observation or calculation procedure), can introduce biases of the same magnitude as the long-term climatic variability of pressure into the series, leading to spurious trends and variability (Young, 1993; Peterson et al., 1998; Slonosky et al., 1999; Vincent et al., 2002).

Considerable international interest in the collection and analysis of surface pressure data has led to the production of new national and international pressure datasets (e.g. Basnett and Parker, 1997; Jones et al., 1999b; Kaplan et al., 2000), individual pressure series (Bärring et al., 1999; Allan et al., 2002; Moberg et al., 2002), as well as atmospheric circulation indicators (Allan et al., 1991; Jones et al., 1997, 1999a) extending back into the 18 th century.

This paper describes the quality control and homogenization of 71 long-term monthly surface pressure series from stations in Canada and Greenland. This data set was constructed with the aim of analysing decadal-scale variability in atmospheric circulation over Canada. With this intention in mind, the series selected for quality control and homogenization were those with a duration of at least 50 years, and were chosen so as to give as complete a spatial coverage as possible, given the limited number of long series in northern Canada. The original data series are described in Section 2. In Section 3, the quality control and homogenization procedures used on these data are described. A comparison with the gridded sea-level atmospheric pressure dataset produced by the Hadley Centre (HadSLP; R. Allan and T. Ansell, personal communication, 2001) using empirical orthogonal functions (EOFs) is presented in Section 4. Section 5 presents circulation indices based on the EOF patterns and examines their trends in time. Section 6 investigates correlations between the various circulation indices and a gridded temperature dataset (New et al., 2000). Discussion and conclusions are presented in Section 7.

\section{DATA PROVENANCE AND MANIPULATION}

The stations selected are shown in Figure 1; as can be seen, the longest series are those in southern and northwestern Canada. Long series from Greenland were also included in order to provide more complete spatial coverage relevant for northeastern Canada. The primary sources of monthly data were the World Weather Records of the Smithsonian Miscellaneous Collections, the Monthly Climatic Data for the World Bulletins, and, more recently, the electronic meteorological report archives of Environment Canada (for the Canadian stations). These data (excluding the Greenland stations) were all recorded at official observing stations of the Meteorological Service of Canada observational network, which started in 1841 for Toronto and in 1873 for other stations across Canada. Although some fragmentary observations exist at stations other than Toronto prior to 1873, taken in part by amateur meteorologists (Slonosky, 2003), and in part by the military regiment of the British Royal Engineers, these data are not included in the present analysis and will be studied separately.

The Environment Canada electronic archives contain data for most Canadian reporting stations from 1953 onwards, but in hourly synoptic format. Therefore, it was necessary to calculate monthly means of air pressure for each station from this data. In the interests of data quality, months with fewer than 21 reporting days of data were discarded, as were days with fewer than three different synoptic reports. In total, over 66000 individual mean monthly pressure values were obtained, with a missing value rate of $5.9 \%$.

Despite the different data sources, there were no significant differences in the standard deviation of data originating from different sources for each station; typical standard deviations of mean monthly pressure ranged from about $2.0 \mathrm{hPa}$ over the Canadian Prairies to greater than $5.0 \mathrm{hPa}$ at some Greenland stations (this difference is due to the greater natural variability in Arctic regions). Data published by the World Weather Records was also corrected for rounding errors, because prior to 1971 the mean monthly pressure was rounded to the nearest millibar (hPa). It was calculated, however, that these rounding errors had no effect on the standard deviation or standard error of mean monthly pressure. 


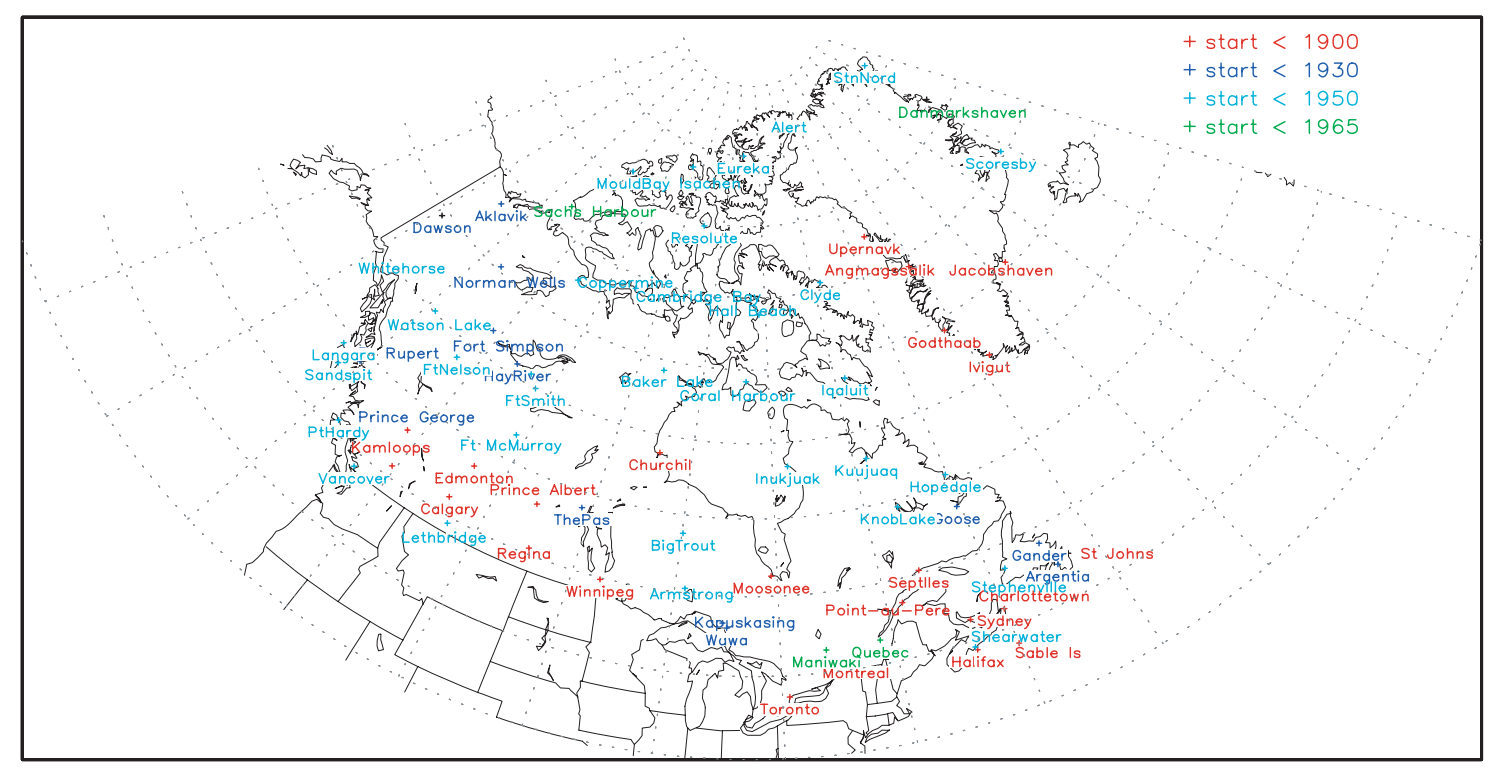

Figure 1. Location of station series

Station-level observations were selected in preference to sea-level values, as it was considered that stationlevel observing was more reliable and, as fewer calculations were involved in obtaining the station-level series, there were fewer opportunities for calculation-related inhomogeneities to occur. This choice did not have an effect on our final results, as all analyses were carried out on monthly anomaly data. In several cases only sea- or station-level observations were available for certain portions of the record; in these cases, either the station information or, if the station information was unavailable, adjustment factors based on monthly mean differences between the different segments of the records were used to relate the segments and produce a uniform station- or sea-level series. Figure 2(a) shows an example for Charlottetown, Prince Edward Island.

At Charlottetown, station-level pressure data was available from 1874 to 1940 . Station data resumed again in 1951, but with a mean long-term value of about $6 \mathrm{hPa}$ lower than before, most likely due to a station relocation. Fortunately, a sea-level pressure record overlaps the broken period, and by calculating monthly adjustment factors (subtracting one series from the other), a complete station-level pressure record was obtained.

Several observation series that started relatively early (in the late 19th or early 20th centuries) ended abruptly; in these cases, when possible, nearby stations were used to complete the series and produce a composite series of longer duration. Monthly mean adjustments were again calculated using the overlapping portions of both series to produce the composite series; the earlier segments were reduced to conform with the later, most modern segment. The example of Point-au-Père, Québec, is shown in Figure 2(b). Station-level data are available from 1874 to 1940, with a sea-level pressure record from 1921 to 1950, after which records cease. However, the nearby station of Bagotville started recording data in 1942; so, using the overlapping period between 1942 and 1950, all three segments of atmospheric pressure were reduced to one continuous record through to the present.

\section{QUALITY CONTROL AND HOMOGENIZATION}

\subsection{Quality control}

Quality control of the newly digitized data was undertaken in a first step by a visual inspection of the pressure time series and by comparing station- and sea-level time series for each location, when available. When both were available, difference series between the two were plotted in order to perform a quality control. Several inhomogeneities were discovered using this technique, including a nationwide inhomogeneity between 1976 

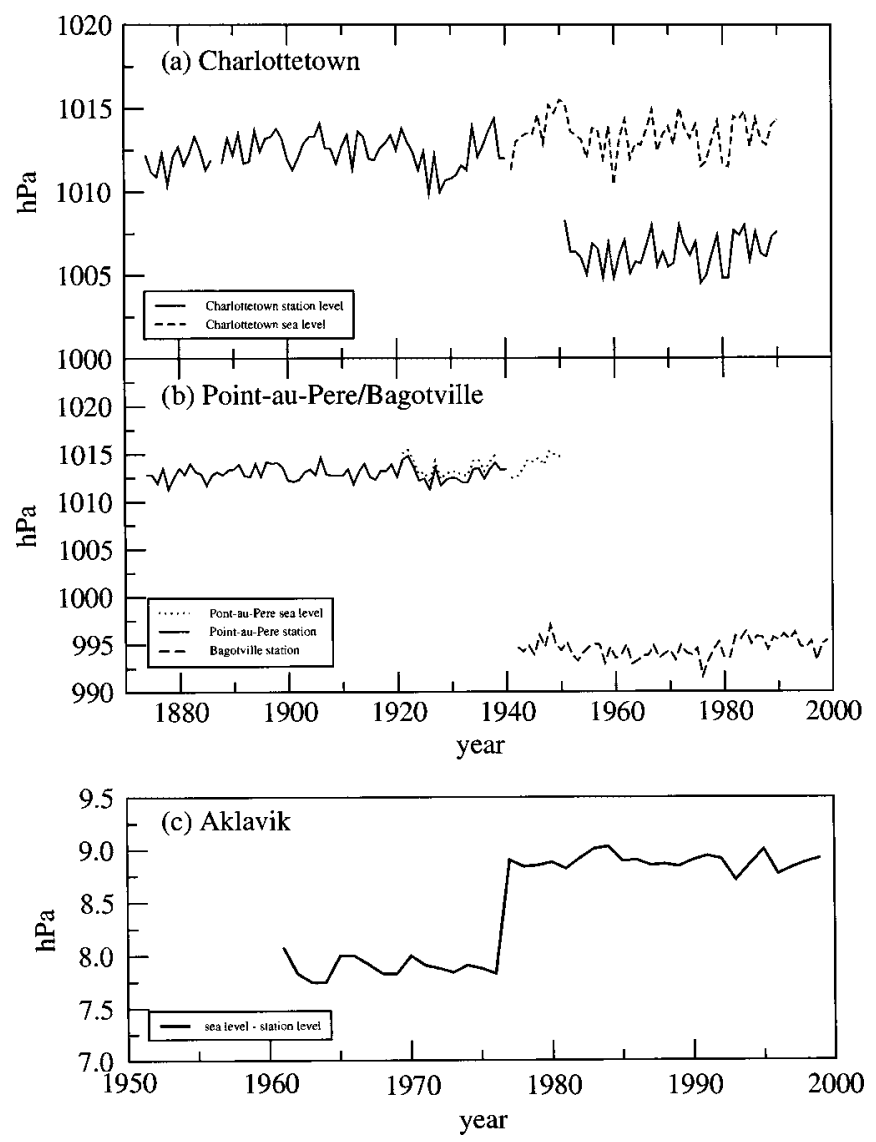

Figure 2. Mean annual atmospheric pressure (hPa) records. (a) Charlottetown, Prince Edward Island, 1874-1990. Station pressure is available from 1874 to 1940 and from 1951 to 1990. An overlapping sea-level record allows computation of a complete station-level record. (b) The nearby sites of Point-au-Père and Bagotville, 1874-2000. Overlapping of the sea- and station-level records allows construction of one complete station record. (c) Aklavik (Inuvik) mean annual sea-level atmospheric pressure minus station-level atmospheric pressure. Note the discontinuity in 1977 when surface pressure reporting was adapted to WMO guidelines (see text)

and 1977 which otherwise may have gone undetected. Note that some conventional homogeneity techniques, relying on reference series (e.g. Caussinus and Mestre, 1996; Alexandersson and Moberg, 1997; Vincent et al., 2002) are unable to detect this kind of widespread inhomogeneity.

In November 1976, computer-generated pressure reduction tables were used for the first time by the Meteorological Service of Canada (formerly the Atmospheric Environment Service), replacing the previous calculations which were made either manually or by using primitive desk calculators. The algorithms used to calculate the station pressure correction and the station to sea pressure reductions were also adapted to World Meteorological Organization (WMO) guidelines at this time, including the addition of plateau correction (Savdie, 1982). The result was a discontinuity in both sea-level and station-level pressure records across all parts of Canada (see Figure 2(c)). The discontinuity between the station-level and sea-level pressure series was detected at almost $80 \%$ of Canadian stations, with an average discontinuity on the order of $0.9 \mathrm{hPa}$; in some cases it was of the order of several hectopascals, especially in colder and higher Arctic regions, where the adjustments from station-level to sea-level pressure were greatest (the largest correction factor was $5.5 \mathrm{hPa}$ at Dawson in northwestern Canada; see also Jones (1987)). If undetected, this discontinuity would have led to spurious trends of atmospheric pressure across large parts of Canada.

An added complication was caused by what was termed the established elevation of a site. This term was used to describe 'the vertical distance above sea level, adopted as the datum level to which barometric 
reports at the station refer' (McMaster, 1975). However, if the established elevation of an office whose cistern was less than $50 \mathrm{ft}(\sim 15 \mathrm{~m})$ in elevation, then the established elevation was arbitrarily assigned as sea level (Upton, 1972; it appears this rule was put in place some time in the 1930s). Furthermore, site relocation of less than $50 \mathrm{ft}$ in height resulted in no new established elevation - a correction factor was assumed to have been added. All this changed on 1 January 1977, when 'established elevation' was replaced by 'station elevation' in accordance with WMO guidelines (Environment Canada, 1976). 'Station elevation' was defined as the 'vertical distance above mean sea level of the datum level to which barometric pressure reports at the station refer'. Mean sea-level (MSL) pressures should not have been affected, but station pressures (for those stations previously at an altitude between sea level and $50 \mathrm{ft}$ ) will have experienced a slight drop (McMaster, 1975).

Several other inhomogeneities due to changes in observing practice were brought to light during the course of this exercise. On 1 January 1935, a new table for reduction to sea level (using the Bigelow method) was first used. Uniformity was not achieved until January 1941, however, when all Canadian stations received new reduction cards during the changeover from reporting of pressures in inches of mercury to hectopascals. These inhomogeneities led Potter (1955) to make a decision to exclude all MSL pressure data prior to 1940 when constructing monthly mean sea-level pressure maps. Potter (1955) also notes that, prior to 1940s, barometers were not inspected regularly, and 'periods of 20 years or more passed without reports on the index'. Godson (1955) notes that MSL pressure during the period 1938-54 had been about 0.4 to $0.5 \mathrm{hPa}$ too high. Another relatively minor inhomogeneity occurred on 30 June 1955 , when a new value of $9.80655 \mathrm{~m} \mathrm{~s}^{-2}$ was introduced for the acceleration due to gravity (the old value was $9.80616 \mathrm{~m} \mathrm{~s}^{-2}$ ). However, it is important to note that our study uses station-level pressure, wherever possible, and inhomogeneities have been corrected using standard homogenization techniques.

\subsection{Homogenization}

The homogenization technique used was that described in detail by Slonosky et al. (1999). This is a semi-objective iterative technique based upon graphical inspection of difference series between neighbouring stations. For each candidate station, four neighbouring stations were chosen for comparison, one in each cardinal direction. Four difference series were calculated, and the graphical results plotted together. If a discontinuity occurred in more than two difference plots, then the jump was attributed to the candidate station. All stations were inspected, all adjustments deemed necessary were applied, and the process repeated to ensure that the discontinuities were correctly attributed. Adjustment factors were calculated to adjust identified inhomogeneous periods to the modern portion of the series. An evaluation of this method, compared with the standard normal homogeneity test (SNHT; Alexandersson and Moberg, 1997) and the Bayesian method developed by Caussinus and Mestre (1996) is given in Slonosky et al. (1999). The results presented in Slonosky et al. (1999) indicate that the iterative graphical method performed as well as the other two methods, and in the case of data-sparse regions it outperformed the other methods as it eliminated the propagation of errors. Furthermore, the iterative graphical method does not require the existence of a homogeneous surrounding series a priori to adjust an inhomogeneous series. It was not possible to apply the SNHT method to the Canadian and Greenland pressures series as the SNHT method relies on the existence of homogeneous references series for comparison purposes, which do not exist for this region prior to the advent of reanalysis products in the 1950s. The Bayesian method developed by Caussinus and Mestre (1996) does not rely on homogeneous reference series, but calculates adjustment factors based on surrounding stations. Although this method of obtaining adjustment factors is usually the preferred one, we were concerned by the possible propagation of errors in the data-sparse regions, as was seen in Slonosky et al. (1999). A concern of the Slonosky et al. (1999) method was the reduction of variability within a series, as the adjustment factors were derived from different portions of the same series, under the assumption that pressure is a conserved variable in the long term. However, as was demonstrated in Slonosky et al. (1999) with much longer series, there were no differences in the variance of the series which were adjusted using the three different techniques. As the pressure characteristics of the high and middle latitudes are similar between the European region studied in Slonosky et al. (1999) and the Canadian region considered in this paper, we assumed that the results obtained concerning the biases and shortcomings of the various homogenization techniques in Slonosky et al. (1999) 
would apply in this study. A final quality control check was carried out by plotting the monthly mean maps for each month and each year, and visually inspecting the plots for outliers.

\subsection{Comparison of regional trends}

Figure 3 shows the differences in regional trends of standardized anomaly pressure data before and after the homogenization process. The regions are divided into northern and southern Canada: northern Canada is defined as the region north of $55^{\circ} \mathrm{N}$, which is approximately the limit of the boreal forest; southern Canada is taken to be south of $55^{\circ} \mathrm{N}$. The data were also separated into eastern and western Canada; eastern Canada is the area east of $100^{\circ} \mathrm{W}$ including Hudson Bay; western Canada is the area west of $100^{\circ} \mathrm{W}$ and east of the Pacific Ocean. The values of the trends are listed in Table I.

It is important to note that there are no trends which are statistically significant at the $95 \%$ level in the homogenized data, whereas several statistically significant trends exist in the raw data, due to data inhomogeneities. Nkemdirim and Budikova (2001), in their analysis of sea-level pressure variations over western Canada (west of $90^{\circ} \mathrm{W}$ in this instance) for the period 1956-93, reported a mean trend of -0.4 $\mathrm{hPa} /$ century in the annual average pressure. This value was non-significant at the $95 \%$ confidence level, although it masked considerable seasonal variation. Our calculated mean annual trends for western Canada are similar, and they are also non-significant at the $95 \%$ confidence level. It is worth noting that our study spans a longer time period (starting between 1897 and 1928 for western Canada, west of $100^{\circ} \mathrm{W}$ ). The results shown in Table I emphasize the extreme importance of rigorous homogenization in any climate data analysis.

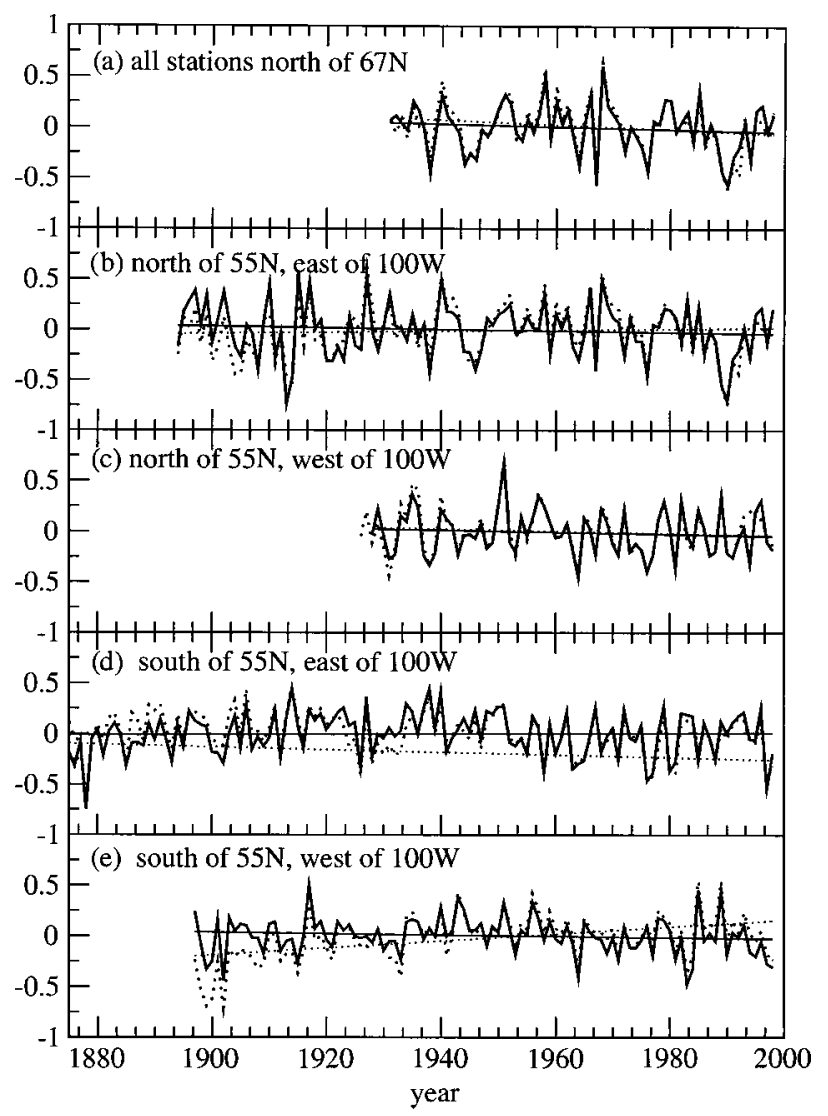

Figure 3. Trend in area-averaged standardized pressure anomalies before (dotted line) and after homogenization (solid line), for (a) all stations north of $67^{\circ} \mathrm{N}$, (b) all stations north of $55^{\circ} \mathrm{N}$, east of $100^{\circ} \mathrm{W}$, (c) all stations north of $55^{\circ} \mathrm{N}$, west of $100^{\circ} \mathrm{W}$, (d) all stations south of $55^{\circ} \mathrm{N}$, east of $100^{\circ} \mathrm{W}$, and (e) all stations south of $55^{\circ} \mathrm{N}$, west of $100^{\circ} \mathrm{W}$ 
Table I. Trends in original and homogenized data ${ }^{\mathrm{a}}$

\begin{tabular}{lcc}
\hline Stations & $\begin{array}{c}\text { Original data (standardized } \\
\text { units per century) }\end{array}$ & $\begin{array}{c}\text { Homogenized data (standardized } \\
\text { units per century) }\end{array}$ \\
\hline North of $67^{\circ} \mathrm{N}$ & -2.85 & -1.23 \\
North of $55^{\circ} \mathrm{N}$, east of $100^{\circ} \mathrm{W}$ & +0.53 & -0.78 \\
North of $55^{\circ} \mathrm{N}$, west of $100^{\circ} \mathrm{W}$ & -1.30 & -1.28 \\
South of $55^{\circ} \mathrm{N}$, east of $100^{\circ} \mathrm{W}$ & $\mathbf{- 1 . 1 7}$ & +0.30 \\
South of $55^{\circ} \mathrm{N}$, west of $100^{\circ} \mathrm{W}$ & $\mathbf{+ 3 . 2 4}$ & -1.30 \\
\hline
\end{tabular}

${ }^{a}$ Values in bold/italic are statistically significant at the $95 \%$ confidence level.

The statistically significant trends in the area-averaged unhomogenized series for southern Canada could lead to false conclusions about the nature of atmospheric variability, trends and climate change.

\section{EOF ANALYSES OF STATION AND GRIDDED DATASETS}

\subsection{Station-based EOFs}

EOF analyses were carried out on the station data. The results are shown in Figure 4; we used the set of stations available from 1948 onwards in order to give the greatest possible spatial representation over northern Canada, where very few stations existed prior to World War II. The data from 65 surface stations in Canada and Greenland were used to create the EOFs. The results from 1941 to 1998 (using 52 stations) and 1932 to 1998 (using 41 stations) are similar; the correlation coefficients between the first two EOFs of the 1948-98 analysis and those of the longer periods range from 0.94 to 0.99 , and the correlation coefficients for EOF 3 range from 0.86 to 0.94 .

All analyses were carried on the correlation matrix to provide equal weighting to all points. The analysis was carried out on monthly anomaly data. Analyses were carried out (not shown) which compare the results obtained using all the calendar months together against results using a seasonal decomposition. The correlations for the leading three EOFs between the monthly analysis and the seasonally decomposed analysis range from 0.99 in winter to 0.90 in summer; given that virtually the same information was recovered in the two instances, it was felt to be more consistent to use the monthly analysis rather than the seasonally decomposed analyses.

The first EOF of the station analysis (Figure 4(a)) is of the same sign over the entire domain, showing a local maximum over northwestern Canada, over the MacKenzie River basin and the Rockies to the north, and in the lee of the Rockies and over the Prairie region further south. When the temporal loadings are high, the positive pressure anomalies are strong. This pressure pattern has been identified by Potter (1955) as the dominant circulation type at monthly scales for the months of November to June.

The configuration of pressure anomalies depicted by EOF 1 of the station data analysis is associated with cold air outbreaks from the Arctic spreading over central and eastern Canada (see Section 6 also; Bonsal et al., 2001). This pattern is somewhat similar, although displaced to the east, to the western North American centre of action of the Pacific-North American (PNA) pattern described by Wallace and Gutzler (1981), a teleconnection pattern based on a rotated EOF analysis of hemispheric-scale gridded pressure data. However, there is no significant correlation in the monthly time series between the first EOF time series coefficients of the station data and the time series of the PNA $(r=0.19)$.

EOF 2 of the station analysis shows a zonal bipole, with negative pressure anomalies in the northeast and over northern Greenland, and positive anomalies in the southeast. There is a clear spatial separation between the first two EOF patterns, suggesting that the western and eastern circulation modes are unconnected. The second EOF has most weight over the western Atlantic region. There is a significant correlation $(r=0.54$; $r=0.63$ for November-March) between the monthly EOF time series associated with this pattern and the time series of the North Atlantic oscillation (NAO), based on the station series of Gilbraltar/Ponta 

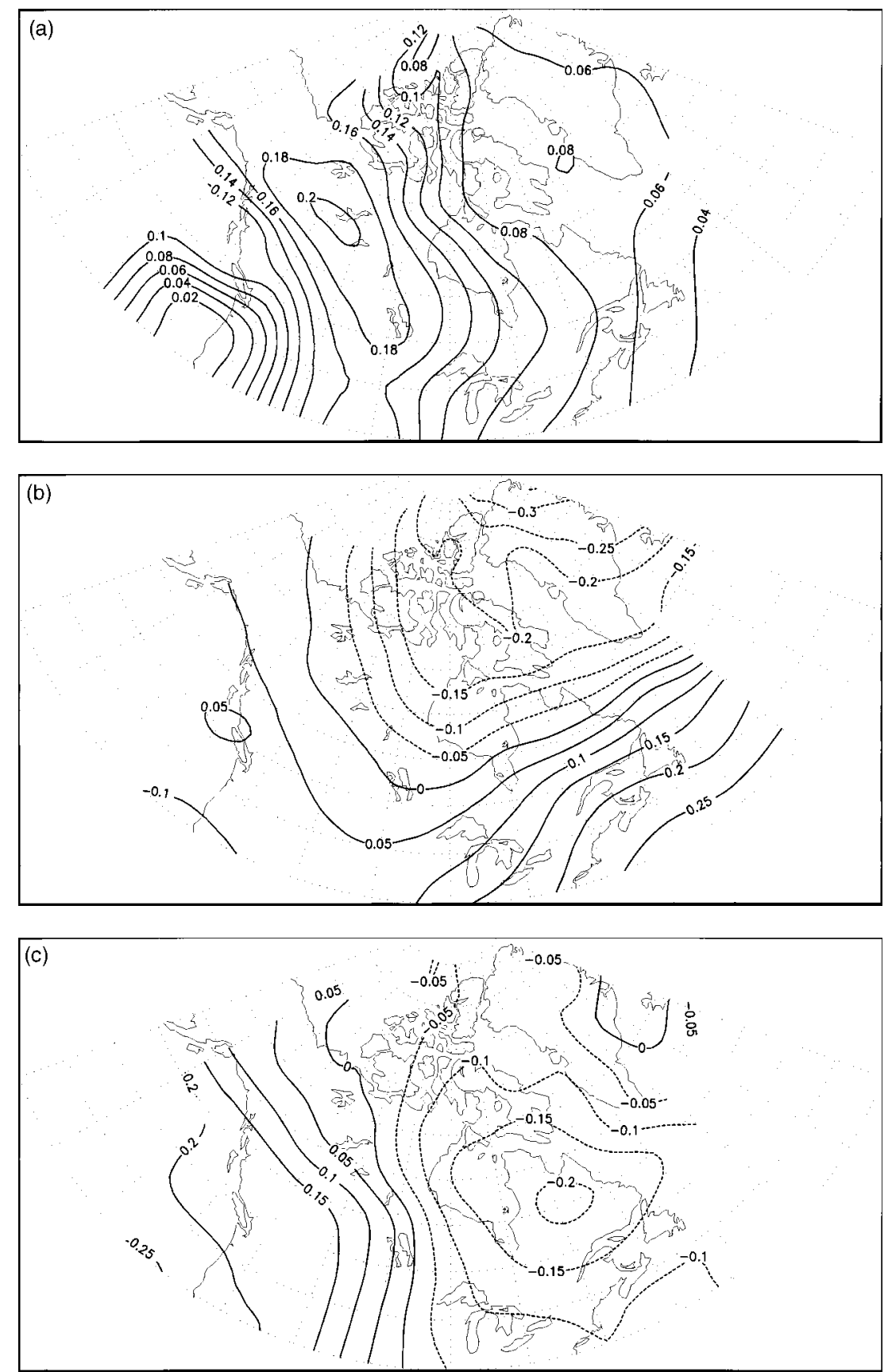

Figure 4. Spatial EOF patterns of 65 Canadian and Greenland surface stations from 1948 to 1998 for (a) EOF 1 (28.4\%), (b) EOF 2 $(19.4 \%)$ and (c) EOF $3(17.6 \%)$

Delgada-Reykjavik (Slonosky and Yiou, 2001). The NAO describes the simultaneous strengthening and weakening of the Icelandic low and Azores high in the subpolar and subtropical North Atlantic respectively (Walker and Bliss, 1932; van Loon and Rogers, 1978; Hurrell, 1995; Jones et al., 1997; Slonosky and Yiou, 2001). The NAO index is calculated as the difference of normalized pressure between the Azores subtropical high and the Icelandic subpolar low. Its importance as the dominant mode of atmospheric 
variability in the Northern Hemisphere has been shown by Barnston and Livezey (1987). The NAO is often considered as a measure of the westerly wind, or zonal flow, over the eastern Atlantic basin, although this is a simplification of the complex North Atlantic circulation dynamics. The correlation between EOF 2 of the station EOF analysis and the NAO teleconnection pattern based on $700 \mathrm{hPa}$ heights originally defined by Barnston and Livezey (1987) is 0.72. The Arctic oscillation (AO; Thompson and Wallace, 1998) is defined as the first principal component of the gridded surface pressure field over the Northern Hemisphere and is also, conceptually, an indicator of Northern Hemisphere zonal flow, although there is considerable controversy as to the dynamic interpretation, or lack thereof, of the AO (Deser, 2000; Ambaum et al., 2001; Itoh, 2002; Rogers and McHugh, 2002). The correlation between EOF 2 of the station analysis and the $\mathrm{AO}$ is 0.70 . There is also a high negative correlation $(r=-0.77)$ between the time series of station EOF 2 and the Baffin Island-west Atlantic (BWA) upper air atmospheric circulation index (Shabbar et al., 1997).

The third EOF pattern shows a meridional or cyclonic pattern, centred over central Quebec and Labrador, but with anomalies of opposite sign over western Canada, suggesting an anomalous meridional flow. This pressure pattern has also been identified by Potter (1955) as the dominant pattern for the months of July, August and September, and may reflect the Hudson Bay's low-pressure centre. The EOF of this pattern also has a significant correlation with the monthly time series of the tropical-North American teleconnection pattern described by Mo and Livezey (1986) $(r=0.61)$.

\subsection{Gridded data EOFs (using HadSLP)}

We also calculated EOFs for a gridded surface air pressure data set produced by the UK Hadley Centre (HadSLP; R. Allan, personal communication, 2001). The Hadley Centre pressure dataset was chosen as it starts in 1873 , has been recently updated to 2001 , and the data have recently undergone rigorous quality control checks, particularly in the Northern Hemisphere (Basnett and Parker, 1997). The spatial EOF patterns of the HadSLP analysis from 1930 to 1998 are shown in Figure 5. The results from 1901-98 and 1950-98 are virtually identical; the correlation coefficients between the first two EOFs of the 1901-98 and 1950-98 analyses are 0.99 , and for EOF 3 the correlation is 0.98 .

There are considerable differences between the leading EOFs of the HadSLP dataset and those from our station-based analyses (Section 4.1). In contrast to the station analyses, the first EOF of HadSLP represents zonal-type flow (Figure 5(a)), somewhat reminiscent of the NAO teleconnection pattern (Barnston and Livezey, 1987) and the AO (Thompson and Wallace, 1997) pattern, although the AO does not have any spatial loadings over southern Canada. The correlation between EOF 2 of HadSLP and the NAO time series is 0.69; between EOF 2 of HadSLP and the AO the correlation is 0.79 , and it is -0.82 for the BWA. Correlation coefficients were calculated between the first three EOFs of our station pressure series and the HadSLP grid, and are shown in Table II.

EOF 2 of HadSLP (Figure 5(b)) is quite similar in concept to EOF 1 of the station data (Figure 4(a)); although in EOF 2 of HadSLP there is a clear east-west dipole, there are again negative loadings over northeastern Canada and Greenland, as there were also in EOF 1 of HadSLP, and there does not appear to

Table II. Correlation coefficients between the EOFs of station pressure series and HadSLPa

\begin{tabular}{lccc}
\hline EOFs stations 1930-98 monthly & \multicolumn{3}{c}{ EOFs HadSLP } \\
\cline { 2 - 4 } & 1 & 2 & 3 \\
\hline 1 & -0.61 & 0.59 & 0.11 \\
2 & 0.80 & 0.43 & 0.12 \\
3 & 0.28 & 0.19 & 0.61 \\
\hline
\end{tabular}

${ }^{\text {a }}$ Values in bold/italic are statistically significant at the $95 \%$ confidence level. 

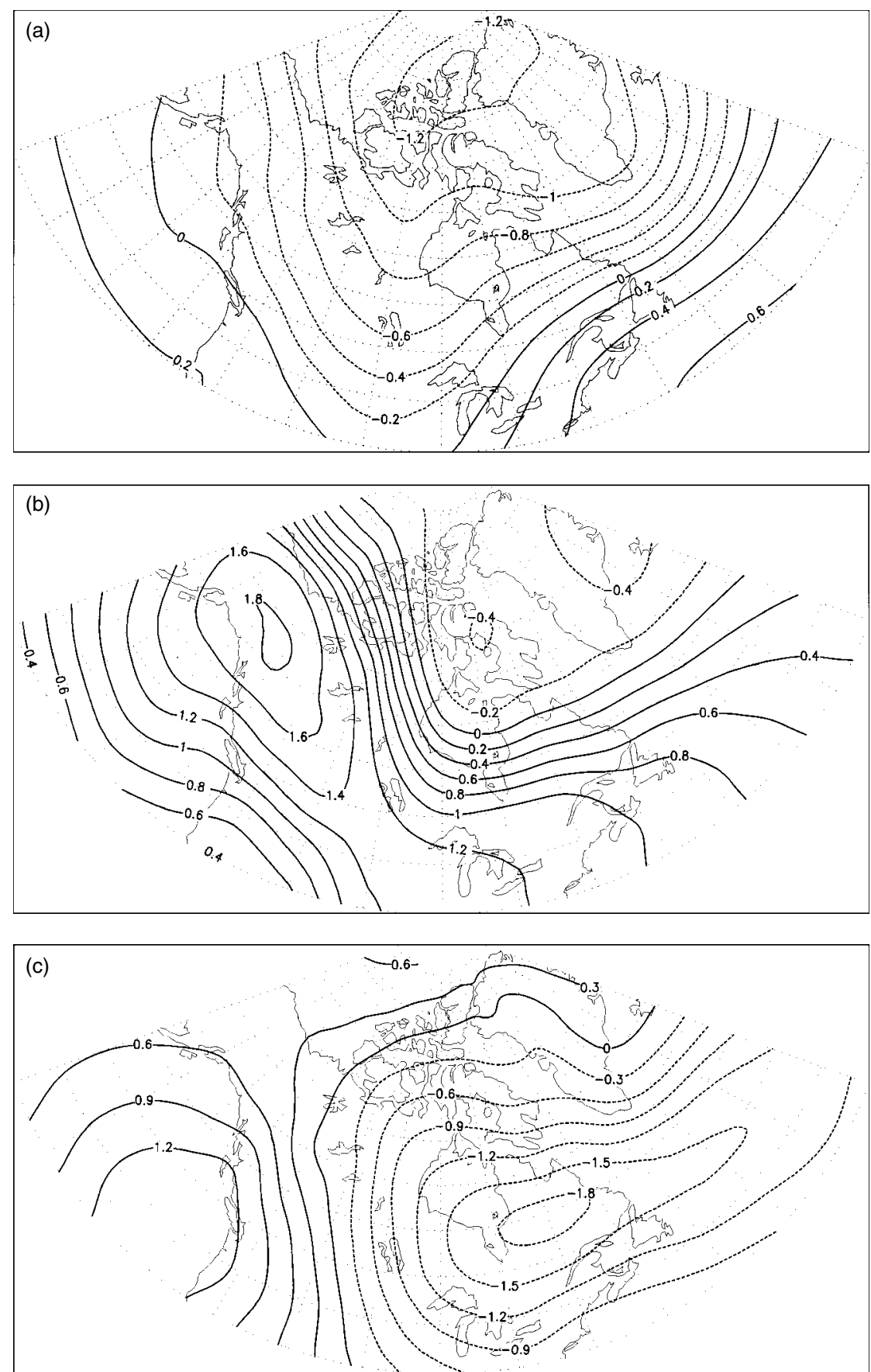

Figure 5. Spatial patterns of an EOF analysis of the HadSLP dataset restricted to $40-90^{\circ} \mathrm{N}$ and $20-180^{\circ} \mathrm{W}$, for the period $1930-98$ : (a) EOF 1 (40.5\%); (b) EOF 2 (15.3\%); (c) EOF 3 (9.3\%)

be as clear a spatial separation between eastern and western circulation modes as there was in the station EOFs. The western centre is further west and does not extend to the same extent over the Prairie region. The correlation between EOF 2 of HadSLP and the PNA is -0.48. EOF 3 of HadSLP (Figure 5(c)) is similar to EOF 3 of the station data, with an east-west dipole and a cyclonic centre over central Quebec and Labrador, 
although the cyclonic centre extends farther east than in EOF 3 of station data, and does not extend as far north. The correlation between EOF 3 of HadSLP and the time series of the tropical Northern Hemisphere (TNH) pattern is -0.51 .

It should be noted that some of the differences in the loading patterns between the HadSLP analysis and the station analysis are undoubtedly due to differences in spatial coverage; fewer of the northern stations were available when the HadSLP dataset was constructed, and they have only been properly investigated, quality controlled and homogenized in this present exercise. HadSLP also contains data from the USA.

These differences, notwithstanding some of the causes described in the above paragraph, raise the question of to what degree the concept of gridded data in itself influences EOF and other variance-based analyses. There is an inherent degree of spatial memory in pressure data; this is higher than for most other meteorological variables and is due to the large-scale nature of the atmospheric circulation. Because synoptic weather systems and the pressure patterns associated with them extend over many hundreds of kilometres, the surface pressure field is smooth and has a much higher degree of spatial autocorrelation than do temperature or precipitation, especially on a monthly scale. This degree of spatial memory is artificially enhanced in the construction of gridded datasets, particularly over data-sparse regions, as there are usually more grid points than there are station data to inform the grid construction processes. An EOF analysis, however, does not 'know' a priori the degree of dependence between grid points in a gridded dataset, and will treat all points as independent observations. This could lead to artificially high EOF spatial loadings over data-sparse regions, leading to patterns that may not be realistic.

The correlations between the time series of the station-based EOFs and the HadSLP EOFs (Table II) were calculated on all months since 1930; results for the periods 1901-98 and 1951-98 are very similar. Because of the large number of observations and the relatively low temporal autocorrelation of pressure, the $p$-value for a correlation to be considered not equal to zero at the $95 \%$ confidence level is 0.08 , a value so low as to be meaningless (Nicholls, 2001). The correlation between station EOF 2 (Figure 6(b)) and HadSLP EOF 1 (Figure 6(c)) is high (0.8) and there is also some correlation between EOF 1 of the stations and EOF 2 of HadSLP $(r=0.59$; Figure 6(a)). The correlation between the third EOFs of both analyses (Figure 6(d)) is also high $(r=0.61)$.

\section{CANADIAN CIRCULATION INDICES}

\subsection{Introduction to the circulation indices}

In order to provide long series of atmospheric circulation indices for long-term studies, atmospheric circulation indices were constructed from selected stations with the longest records available to date. These series were based on stations located near the 'centres of action' identified by the EOF analysis described in Section 4. A northwest index ('NW') was constructed based on the average of the standardized pressure anomaly series of Dawson, Fort Simpson, Prince Albert and Hay River (Figures 1 and 6(a)); this index (NW) starts in 1911. A zonal index for eastern Canada ('East') was constructed by subtracting the average of the standardized pressure anomaly of Godthaab and Jacobshaven from the average of the standardized pressure anomaly series of Sydney and Halifax (Figures 1 and 6(b)); this index starts in 1875. A meridional index ('Meridional') was constructed by subtracting the mean of the standardized pressure anomaly series of Edmonton and Port Hardy from the mean of the standardized pressure anomaly of Sept-Iles and Point-au-Père (Figures 1 and 6(d)); this index starts in 1898. The station-based NAO (Wanner et al., 2001) is also included as a station-based index; the data used here are those from Slonosky and Yiou (2001) and are shown in Figure 6(b).

Table III shows the correlations between these station-based atmospheric circulation series and the leading EOFs of the analyses described in the previous section for the months of November to March. The AO, which is based on a hemispheric-scale EOF analysis of gridded pressure data, is also included (Figure 6(c)).

There are high correlations between the NW index and EOF 1 of the station analysis and EOF 2 HadSLP. The Eastern zonal index is well correlated with EOF 2 of the station analysis, EOF 1 of HadSLP and the AO (the AO itself is also well correlated with EOF 2 of the station analysis and EOF 1 of the HadSLP analysis). 


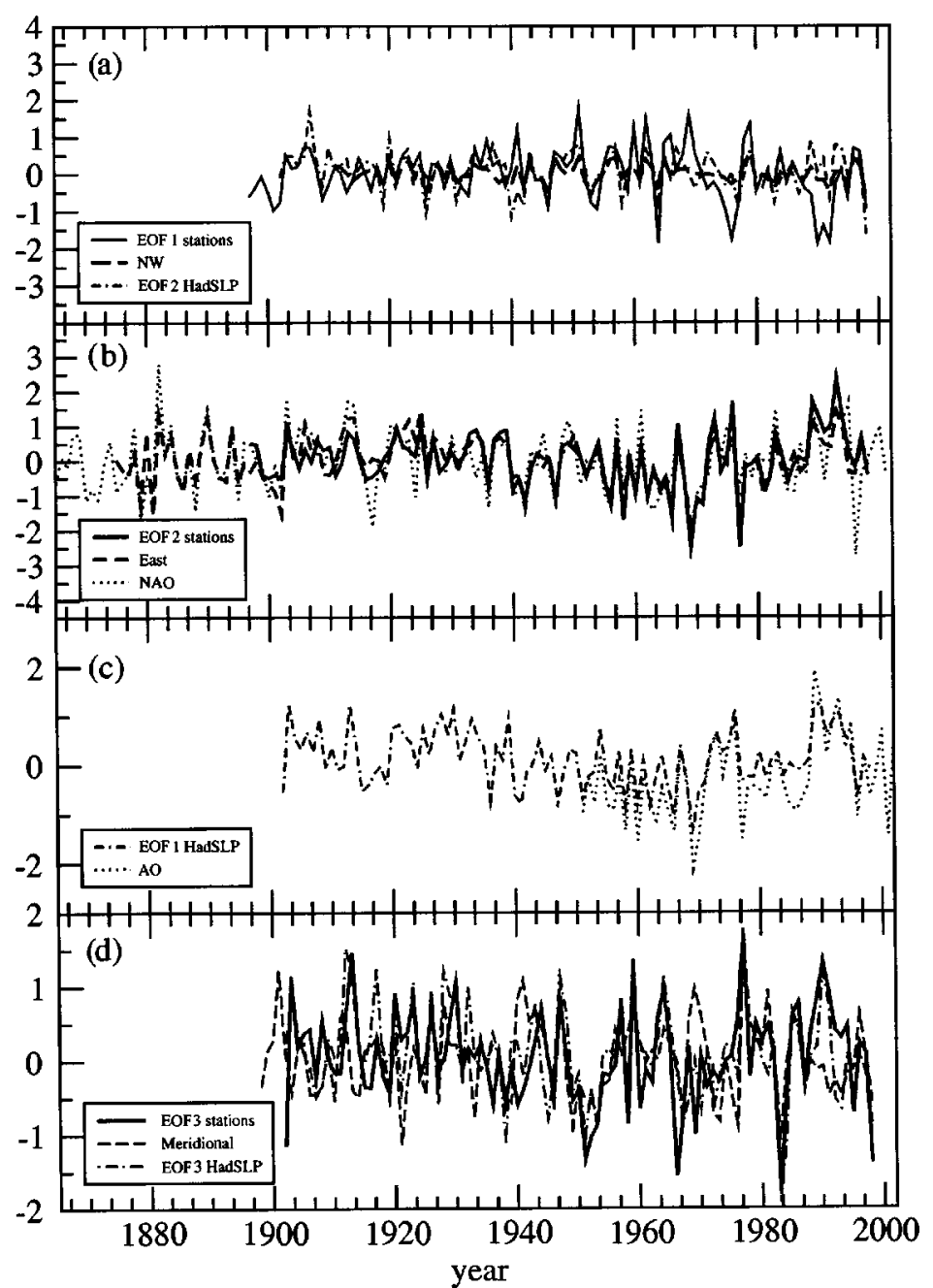

Figure 6. Temporal variations of surface atmospheric circulation indices, averaged over November to March, for (a) northwest type circulation indices (Northwest, EOF 1 stations and EOF 2 HadSLP), (b) eastern zonal-type circulation indices (EOF 2 stations, East and the NAO), (c) central zonal-type circulation indices (EOF 1 HadSLP, AO) and (d) meridional-type circulation indices (EOF 3 stations, Meridional, EOF 3 HadSLP)

Table III. Correlation coefficients between the EOFs and station-based circulation indices ${ }^{\mathrm{a}}$

\begin{tabular}{|c|c|c|c|c|c|c|c|c|}
\hline \multirow{2}{*}{$\begin{array}{l}\text { 1950-98 } \\
\text { November-March }\end{array}$} & \multicolumn{3}{|c|}{ EOF stations } & \multicolumn{3}{|c|}{ EOFs HadSLP } & \multirow[t]{2}{*}{ NAO } & \multirow[t]{2}{*}{$\mathrm{AO}$} \\
\hline & 1 & 2 & 3 & 1 & 2 & 3 & & \\
\hline Northwest & 0.80 & -0.00 & 0.38 & -0.32 & 0.75 & 0.16 & -0.16 & -0.11 \\
\hline East & -0.27 & 0.95 & 0.18 & 0.79 & 0.41 & 0.08 & 0.62 & 0.71 \\
\hline Meridional & 0.35 & -0.50 & +0.60 & -0.37 & 0.07 & 0.40 & -0.34 & -0.34 \\
\hline NAO & -0.32 & 0.63 & 0.08 & 0.68 & 0.15 & 0.06 & & \\
\hline $\mathrm{AO}$ & -0.42 & 0.75 & 0.23 & 0.82 & 0.29 & 0.04 & & \\
\hline
\end{tabular}

${ }^{\text {a }}$ Values in bold/italic are statistically significant at the $95 \%$ confidence level. 
Table IV. Trends in winter-season (November-March) atmospheric circulation indicators ${ }^{\mathrm{a}}$

\begin{tabular}{lcc}
\hline & \multicolumn{2}{c}{ Trend (standardized units per century) } \\
\cline { 2 - 3 } & $1951-98$ & $1901-98$ \\
\hline Northwest (since 1911) & -0.38 & -0.14 \\
East & $\mathbf{+ 1 . 8 5}$ & -0.44 \\
Meridional & -0.08 & -0.02 \\
Stations EOF 1 & $\mathbf{- 2 . 0}$ & -0.37 \\
Stations EOF 2 & $\mathbf{+ 2 . 7}$ & -0.00 \\
Stations EOF 3 & +1.3 & -0.12 \\
HadSLP EOF 1 & $\mathbf{+ 1 . 7 3}$ & -0.28 \\
HadSLP EOF 2 & $\mathbf{- 0 . 3 7}$ & -0.34 \\
HadSLP EOF 3 & $\mathbf{- 0 . 1 1}$ & $\mathbf{+ 0 . 4 2}$ \\
NAO & $\mathbf{+ 1 . 7 1}$ & -0.32 \\
AO & $\mathbf{+ 2 . 4 4}$ & \\
\hline
\end{tabular}

a Values in bold are statistically significant at the $90 \%$ confidence level. Values in italic are statistically significant at the $95 \%$ confidence level.

There is also a high negative correlation with the BWA ( -0.79 ; not shown). The Meridional index does not correlate particularly well with any of the other indices, although the highest correlation is with EOF 3 of the station analysis. It may be noted that the NAO, based much further east over the eastern Atlantic and western Europe, does not correlate especially well with any of the circulation indices based over Canada; the highest correlations are with EOF 2 of the station analysis and EOF 1 of the HadSLP analysis.

\subsection{Variability and trends in circulation indices}

Table IV shows the trends for 1901-98 and 1951-98 of the time series shown in Figure 6. Although many of the circulation indices and EOFs, especially the zonal-type circulation indices (such as East, EOF 2 of the station analysis, EOF 1 HadSLP, and the AO), show statistically significant positive trends at the $95 \%$ level ( $z$-values >1.96) over the period 1951-98, only EOF 3 of HadSLP shows a statistically significant trend at the $90 \%$ confidence level over the course of the entire 20th century. An examination of Figure 6(b) and (c) shows that the period from 1950 to roughly 1970 marks a notably negative phase of the zonal circulation indicators, and the period 1980-95 marks an extreme positive phase; there is, of course, a marked positive trend between these two phases. However, these positive and negative phases, when considered on a century scale in Figure 6(b), do not appear to be hugely out of the ordinary.

The statistically significant increasing trend in EOF 2 of the station series from 1951 to 1998 during winter could partially explain some of the cooling over northeastern Canada during the second half of the 20th century (see Section 6; Zhang et al., 2000). EOF 3 of the station series also shows an increasing trend (nonsignificant) - this might indicate a strengthening of the low-pressure centre over Quebec, Labrador and the Labrador Sea, and increased cyclonic circulation over this area.

\section{CIRCULATION LINKS WITH TEMPERATURE AND IMPLICATIONS FOR CLIMATE CHANGE}

Correlation maps were calculated between the circulation indices described above and a gridded temperature dataset, taken from New et al. (2000), over the Canada-Greenland domain. These correlation maps, calculated over the period 1931-98, show areas of highly significant correlation between the circulation indices and temperature on the monthly and seasonal time scales (Figure 7). The relationship between temperature and the circulation pattern defined by EOF 1 (Figure 4(a)) of the station series (Figure 7(a)-(d)) is consistent 

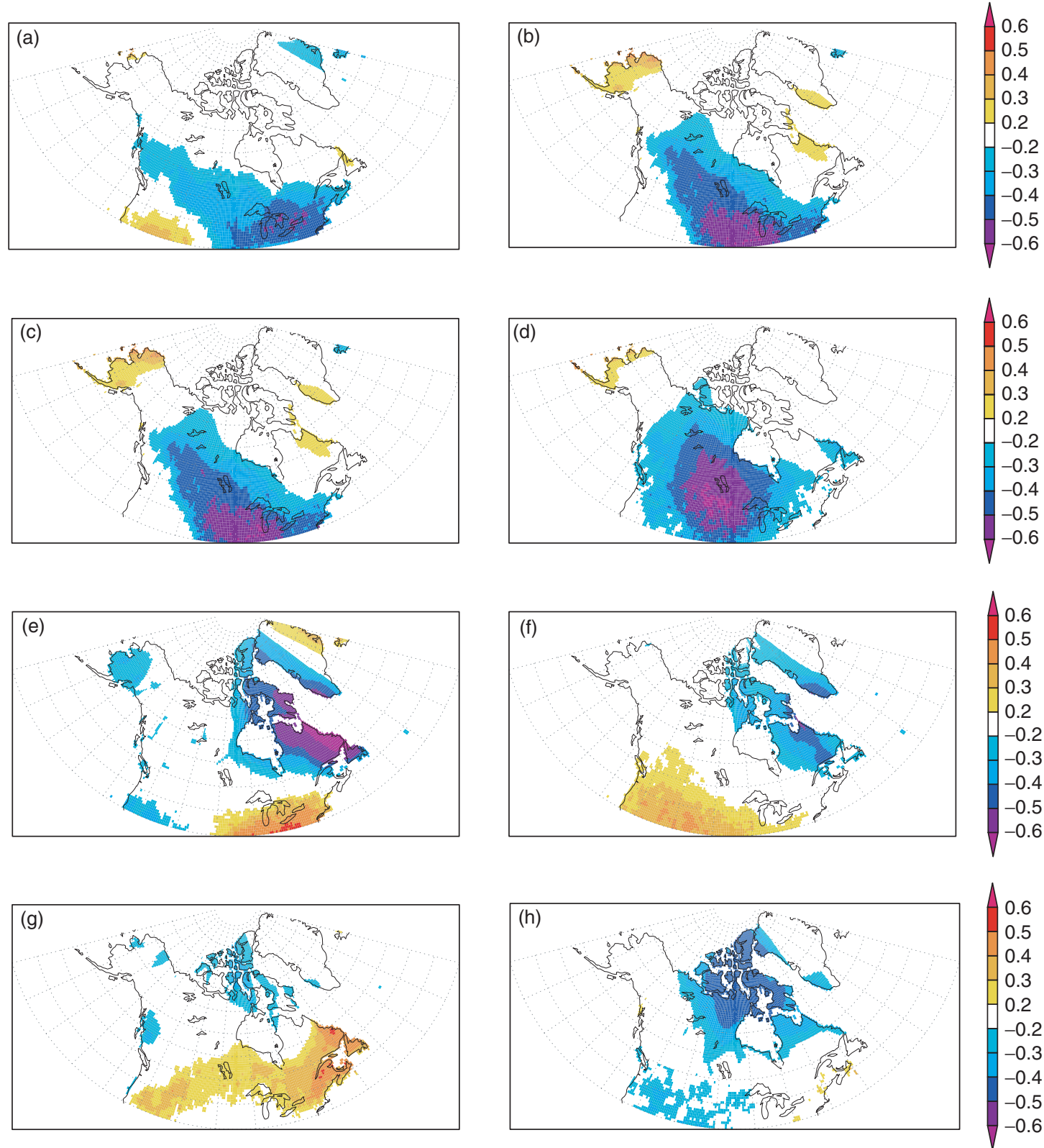

Figure 7. Correlation maps (1932-98) between temperature and: (a) EOF 1 stations winter; (b) EOF 1 stations spring; (c) EOF 1 stations summer; (d) EOF 1 stations autumn; (e) EOF 2 stations winter; (f) EOF 2 stations spring; (g) EOF 2 stations summer; (h) EOF 2 stations autumn; (i) EOF 3 stations winter; (j) EOF 3 stations spring; (k) EOF 3 stations summer; (l) EOF 3 stations autumn; (m) NAO winter; (n) NAO spring; (o) NAO summer; (p) NAO autumn; (q) EOF 1 annual; (r) EOF 2 annual; (s) EOF 3 annual; (t) NAO annual.

All coloured areas are statistically significant at the $95 \%$ confidence level

throughout the year, with high negative correlations over most of central and southern Canada. When the pressure is higher than normal over the Canadian northwest and Mackenzie basin (positive EOF 1 of the stations analysis), the anticyclonic pressure patterns lead to cold air advection from the Arctic regions over southern Canada and much of central North America. Conversely, when the high-pressure system over this region is weaker than normal (negative EOF 1 of the stations analysis), cold air advection from the north is reduced and warmer air advection from the south is encouraged by the anomalous cyclonic flow. This 
advection effect is clearly present throughout the year (Figure 7(a)-(d)) and is a major influence on monthly temperatures over all of central Canada. For convenience, seasonally averaged correlations maps are shown here, but monthly correlations maps (not shown) display correlation coefficients above 0.6 over large areas of central and southern Canada for every month of the year; these correlation coefficients are somewhat smoothed and reduced in the seasonally averaged maps. All coloured areas in Figure 7 have statistically significant correlations between temperature and the corresponding EOF/circulation index.

The correlations between surface temperature and circulation pattern described by EOF 2 of the station series (Figure 4(b)) show more seasonal differences (Figure 7(e)-(h)). The correlation pattern in winter reflects the western domain of the typical winter NAO/AO and temperature quadrupole correlation pattern (Hurrell, 1995; Thompson and Wallace, 1998; Stephenson et al., 2000; Bonsal et al., 2001; Slonosky and Yiou, 2001) with negative correlations over northeastern Canada and Greenland, and positive correlations over southeastern Canada and the northeastern USA (see also Figure 7(m), which is very similar to Figure 7(e)). Again, these correlations can be explained by the advection of cold polar air over the northern regions when the north-south pressure gradient over the North Atlantic is greater than normal (a strong Icelandic low leading to cyclonic circulation over the northern North Atlantic) and vice versa. This correlation pattern continues, with reduced strength, through the spring both for EOF 2 of the stations analysis (Figure 7(f)) and the NAO (Figure 7(n)), although the area of positive correlation shifts to the northwestern USA. A difference can be seen in summer and autumn, however. Although there are few areas of statistically significant correlation between temperature and the NAO in summer (Figure 7(o)), there exist large areas of significant positive correlation over eastern Canada with the more regionally defined EOF 2 circulation pattern and summer temperature (Figure 7(g)). This suggests that regional circulation indices may be of more value in understanding circulation-climate links in summer, when the large-scale atmospheric circulation is less well-organized and acts on smaller scales than in winter. In summer, the land mass is warmer than the ocean, and leads to a reversal of the sign of the correlation; strong westerly winds lead to the advection of warm continental air over eastern Canada, whereas weaker westerlies allow more advection of cool oceanic air. Differences in the influence of the two circulation patterns on temperature can also be seen in the autumn months, when the correlation pattern between surface temperature and EOF 2 of the stations analysis reverts to the winter mode with large areas of negative correlation over northern Canada (Figure 7(h)). Meanwhile, the correlation pattern between autumn temperature and the NAO shows negative correlations over Greenland and positive correlations over much of southern and eastern Canada (Figure 7(p)).

There are also statistically significant correlations between the circulation pattern defined by EOF 3 of the stations analysis (Figure 4(c)) and temperature over large areas of Canada that change with the seasons (Figure 7(i)-(1)). In winter, there are large areas of statistically significant positive correlation over northwestern Canada (Figure 7(i)). The correlation patterns are less similar in spring and summer (Figure 7(j) and $(\mathrm{k})$ ), although the autumn pattern (Figure 7(1)) is much stronger, with large areas of negative correlation over all of Canada east of $100^{\circ} \mathrm{W}$.

The seasonal trends in these circulation indices are shown in Table V. Apart from EOF 1 of the station series on an annual basis, there are no statistically significant trends in the station-based EOF circulation patterns over the period 1901-98, although there is a highly significant negative trend in the winter NAO over the 1901-98 period. With regard to the 1951-98 winter period, there is a negative trend in EOF 1 of the stations and a positive trend in EOF 2, both of which are statistically significant at the $90 \%$ level. There is also a springtime positive trend in EOF 2, significant at the 95\% level.

Detailed analyses by Zhang et al. (2000) show increasing temperatures over most of southern Canada in all seasons over the period 1900-98. Table V shows negative trends in EOF 1 (significant at the 90\% level) over the 1901-98 period on an annual basis, which according to the correlation maps shown in Figure 7(a)-(d), would lead to increasing temperatures over much of southern Canada, in agreement with the results found by Zhang et al. (2000).

Over the more recent period, 1950-98, Zhang et al. (2000) also showed notable trends of cooling temperatures over northeastern Canada in winter and spring, strong warming trends over all of western Canada in winter and spring, and weaker warming trends over the entire country in summer. There were also weak cooling trends over southern Canada and weak warming trends over northern Canada in autumn. 

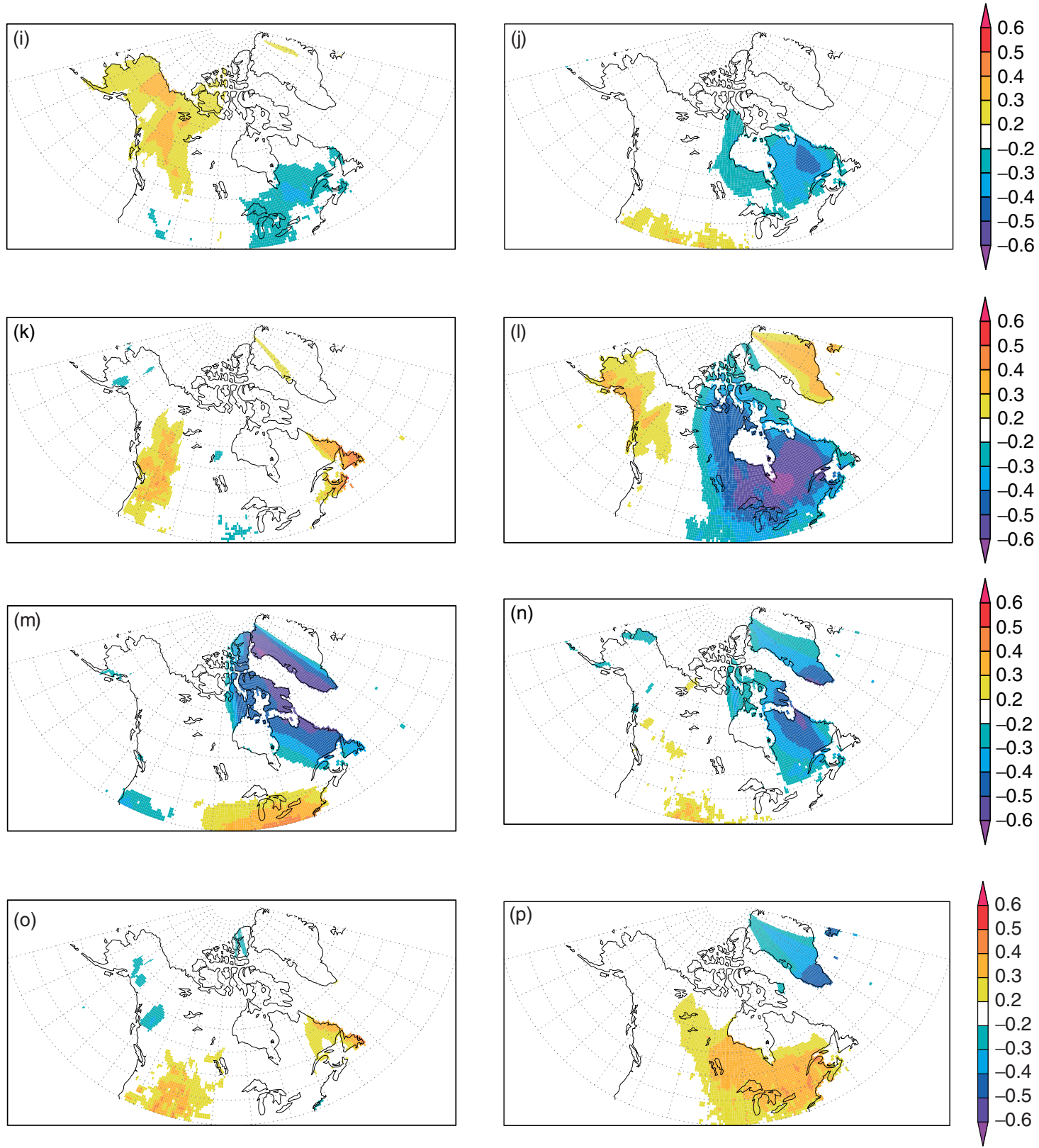

Figure 7. (Continued)

The statistically significant positive trends in the winter and spring values of EOF 2 of the station analysis over the 1951-98 period (Table V), together with the increasing trend of the NAO over this period (nonsignificant), the decreasing trend of EOF 1 (significant at the $90 \%$ level) and the correlation maps between these circulation indices and temperature (Figure 7), support the hypothesis that some of the trends in temperature, as described by Zhang et al. (2000), are related to trends in the circulation indices. For example, significant decreasing trends in EOF 1 in winter (Table V) suggest warming over southern Canada and the Prairies (Figure 7(a)), somewhat similar to what was found by Zhang et al. (2000). In addition, the statistically significant positive trends of EOF 2 in winter and spring may be linked to the significant cooling over northeast Canada and Labrador (Figure 7(e) and (f)), as identified by Zhang et al. (2000). 

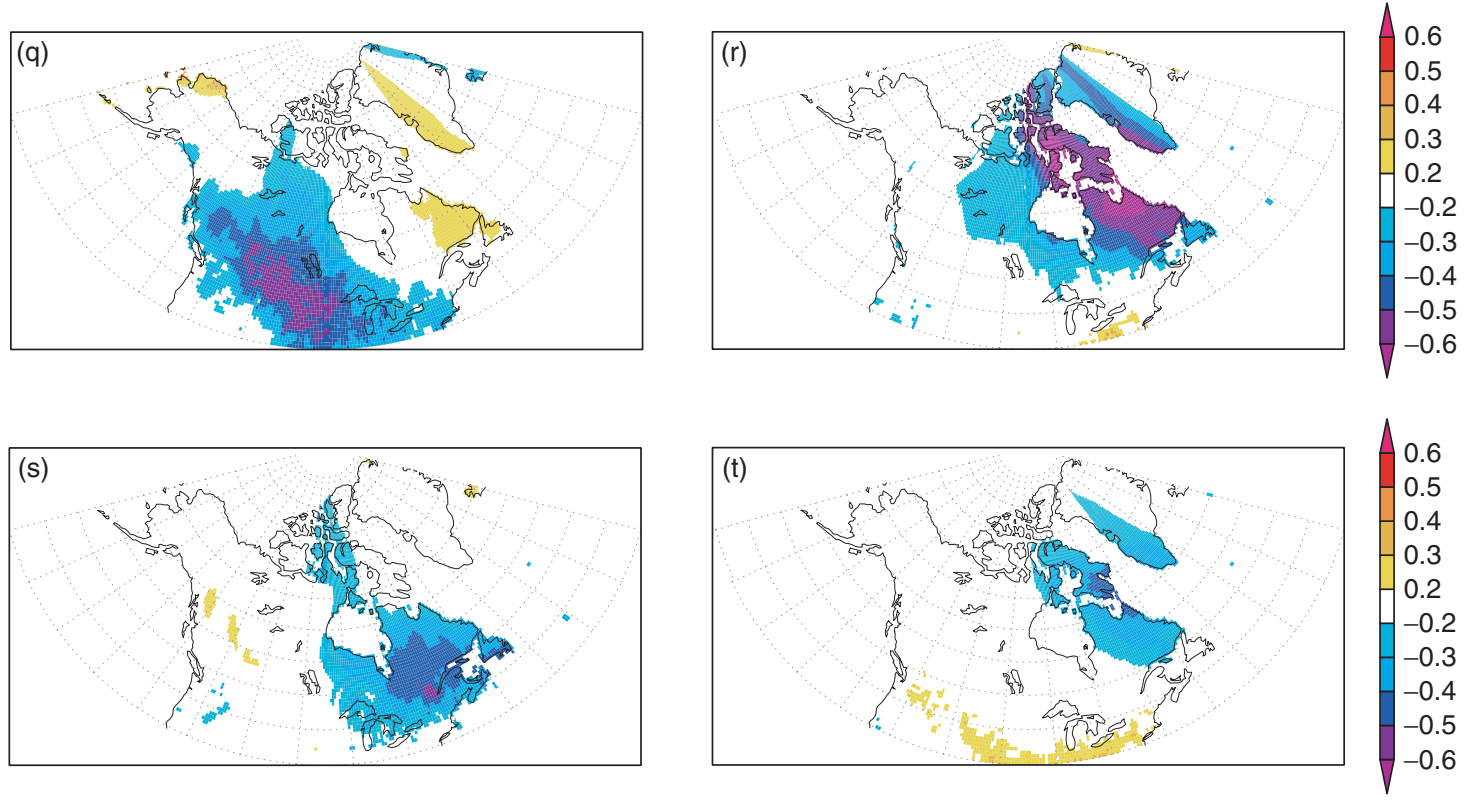

Figure 7. (Continued)

Table V. Trends in seasonal atmospheric circulation indices (standardized units per decade), 1901-98 (1902 for winter series) and 1951-98 (1952 for winter series) ${ }^{\mathrm{a}}$

\begin{tabular}{|c|c|c|c|c|c|}
\hline & Winter (DJF) & Spring (MAM) & Summer (JJA) & Autumn (SON) & Annual \\
\hline \multicolumn{6}{|l|}{$1901-98$} \\
\hline Stations EOF 1 & -0.34 & -0.35 & -0.12 & -0.07 & -0.23 \\
\hline Stations EOF 2 & -0.19 & -0.30 & +0.03 & -0.27 & -0.11 \\
\hline Stations EOF 3 & -0.18 & -0.10 & +0.18 & -0.05 & -0.02 \\
\hline \multicolumn{6}{|l|}{$1951-98$} \\
\hline Stations EOF 1 & -1.95 & -1.29 & -0.19 & +0.22 & -0.80 \\
\hline Stations EOF 2 & +2.37 & +1.88 & +0.07 & -1.30 & +0.77 \\
\hline Stations EOF 3 & +1.39 & -0.30 & -0.18 & -0.16 & +0.22 \\
\hline NAO (1901-98) & -0.82 & -0.11 & +0.28 & +0.22 & -0.08 \\
\hline NAO (1951-98) & +1.41 & +0.23 & +0.24 & -1.23 & +0.19 \\
\hline
\end{tabular}

${ }^{a}$ Values in bold are statistically significant at the $90 \%$ confidence level. Values in italic are statistically significant at the $95 \%$ confidence level.

There is also an increase in EOF 3 of the station analyses during winter over the period 1951-98 (nonsignificant). Figure 7(i) shows significant positive correlation between EOF 3 and winter temperatures, centred over the MacKenzie basin. This could account for some of the very strong warming in this region over the same period $\left(+3.0^{\circ} \mathrm{C}\right.$ in 50 years), as shown by Zhang et al. (2000), although the magnitude of the warming in this region appears unusual - global warming may be a factor also.

Other statistical trends (non-significant) shown in Table $\mathrm{V}$ include a negative trend in EOF 1 and a positive trend in EOF 2 over the summer during the period 1951-98; these imply warming over most of Canada in summer, as was found by Zhang et al. (2000). Finally, a positive trend in EOF 1 and a negative trend in EOF 2 in autumn, coupled with the autumn correlation maps (Figure 7(d) and 7(h)), suggest a warming in the north and cooling in the south, again as is seen by Zhang et al. (2000). 


\section{DISCUSSION AND CONCLUSIONS}

The importance of the tedious, but fundamentally necessary work of carefully scrutinizing station meteorological data for errors and inhomogeneities before applying these data to climatic analyses is demonstrated in this paper. Several large-scale inhomogeneities were discovered in the 71 monthly mean surface-level pressure series analysed here, including a widespread inhomogeneity due to a change in observing practice between 1976 and 1977. These inhomogeneities introduced spurious trends in the regional pressure tendencies which could affect climate analyses that rely upon surface pressure, particularly of atmospheric circulation.

EOF analyses of our station series were undertaken and these were compared with a gridded dataset from the UK Hadley Centre. The results showed considerable differences in the dominant EOF pressure patterns for Canada and Greenland. It is suggested that these differences may be related to extrapolation of gridded data over data-sparse regions. There are few observing stations in the high Arctic and over ocean areas, although the situation is improving with the considerable efforts of the international data community to incorporate marine data, non-standard meteorological data and to digitize and quality control the realms of paper records in the meteorological and other archives of the world. However, all these efforts will never be able to recover data and observations that simply do not exist. Reanalysis projects do go some way to estimating what may have been happening in data-sparse regions, and they generate plausible estimates. Nevertheless, the scientific community should not lose sight of the fact that these are estimates, and that we will not know from instrumental records what the true multi-decadal to century-scale variability is over, e.g. the Arctic, until another 30 to 50 years of observations have been recorded. Even gridded observational data products (such as the temperature data used to calculate the correlation maps in Section 5.2) should be treated with caution, as the number of independent observing stations informing the grid construction procedure is often much less, sometimes by several orders of magnitude, than the number of grid points contained in the grid over data-sparse regions. The number of degrees of freedom in a grid is thus artificially enhanced in a grid over data-sparse regions. Note that this is a problem independent of the equal-area weighting problem faced by gridded data in high latitudes. This is an effect that increases as one goes further back in time, with fewer and fewer observing stations operating in the first half of the 20th century. It is a problem that may become worse if governments continue to cut back observing stations as they have done, particularly in Canada, through the 1990s.

The first three modes of variability recovered from the station-based EOF analysis do, in fact, make sense physically as well as mathematically and have dynamical interpretations. They also have simple pattern loadings. The first circulation pattern relates to the ridge of high pressure over northwestern Canada to the lee of the Rockies, centred over the MacKenzie basin. In its positive phase this is a synoptic pattern associated with cold air outbreaks over most of central Canada and the USA in winter, and is the dominant pattern in the monthly mean pressure field for the months of November to June. The second circulation pattern relates clearly to the mean zonal flow over the western Atlantic basin, with isolines concentrated along the St Lawrence Valley-Newfoundland/Labrador storm track. The third atmospheric circulation pattern is a cyclonic meridional flow centred on Hudson Bay.

Station-based atmospheric circulation indices were constructed based on the areas of maximum variability seen in the EOF analyses. These station-based indices have longer records and are more easily updated than the EOFs of the EOF analysis. Trends in the station-based indices, the EOFs of the station analysis and the gridded HadSLP analysis, as well as the AO and the NAO, were examined both over the past 50 years and the past 100 years. Statistically significant trends were identified over the winter period (November-March) from 1951 to 1998 in the following circulation indices: Eastern zonal index, stations EOF 1, stations EOF 2, NAO, AO, HadSLP EOF 1 and HadSLP EOF 2. However, no trends were statistically significant during winter over the longer time period of 1901-98, except for EOF 3 of HadSLP.

Correlation maps show that these three patterns of circulation are significantly related to temperature variability over Canada. The first pressure pattern is highly correlated with temperature over southern Canada and central North America in all seasons. The second pattern is associated with temperature variability in eastern Canada and the northwestern Atlantic, with negative correlations over northeastern Canada and positive correlation over southern Canada in winter; this pattern also shows positive correlations over much 
of eastern Canada in summer. The third atmospheric circulation pattern is related to temperature variability in northern and central Canada, particularly in autumn and winter. The implied direction of the temperature trends suggested by the trends in the atmospheric circulation and the correlations maps confirms the independent analysis on temperature trends over Canada (Zhang et al., 2000), although the magnitude of the warming in some cases can probably not be explained solely by changes in circulation.

It is clear that in order to understand the cause of the temperature trends over Canada, which differ by region and season, it is necessary to understand the variability of the atmospheric circulation. Regional circulation indices, based on analyses over specific regions, provide better diagnostic results in explaining the variability of temperature on a regional scale in non-winter months than do larger scale indices based on the circulation over the entire hemisphere. This is to be expected, as the circulation in non-winter months is less well-organized than in winter, and more prone to regional variations.

\section{ACKNOWLEDGEMENTS}

We would like to thank Francis Zwiers and Val Swail for their support of this work, Roberta McCarthy and Malcolm Geast for help in tracking down sources, and Rob Allan and Tara Ansell of the Hadley Centre for providing the HadSLP data. The last 5 years of the NAO series were obtained from Tim Osborn's Website at CRU (http://www.cru.uea.ac.uk/timo/projpages/nao_update.htm), the AO series was obtained from the annular modes Website (http://horizon.atmos.colostate.edu/ao/) and the teleconnection time series from the NOAA Climate Prediction Center Website (http://www.cpc.noaa.gov/data/teledoc/telecontents.html). The figures were produced using GrADS and XMGrace freewares. This paper is dedicated to Ignacio Lozano.

\section{REFERENCES}

Alexandersson H, Moberg A. 1997. Homogenization of Swedish temperature data. Part I: a homogeneity test for linear trends. International Journal of Climatology 17: 25-34.

Allan RJ, Nicholls N, Jones PD, Butterworth IJ. 1991. A further extension of the Tahiti-Darwin SOI, early SOI results and Darwin pressure. Journal of Climate 4: 743-749.

Allan RJ, Reason CJC, Carroll P, Jones PD. 2002. A reconstruction of Madras (Chennai) mean sea-level pressure using instrumental records from the late 18th and early 19th centuries. International Journal of Climatology 22: 1119-1142.

Ambaum MH, Hoskins PBJ, Stephenson DB. 2001. Arctic oscillation or North Atlantic oscillation? Journal of Climate 14: $3495-3507$.

Barnston AG, Livezey RE. 1987. Classification, seasonality and persistence of low-frequency atmospheric circulation patterns. Monthly Weather Review 115: 1083-1126.

Bärring LP, Jönsson C, Acheberger M, Ekström H, Alexandersson H. 1999. The Lund instrumental record of meteorological observations: reconstruction of monthly sea-level pressure 1780-1997. International Journal of Climatology 19: 1427-1443.

Basnett TA, Parker DE. 1997. Development of the global mean sea level pressure data set GMSLP2. Hadley Centre of the UK Meteorological Office for Climate Research, Technical Note 79. Hadley Centre for Climate Prediction and Research, Meteorological Office, Bracknell, UK.

Bonsal BR, Shabbar A, Higuichi K. 2001. Impacts of low frequency variability modes on Canadian winter temperature. International Journal of Climatology 21: 95-108.

Caussinus H, Mestre O. 1996. Towards new tools and methodologies for relative homogeneity testing. In First Seminar for Homogenization of Surface Climatological data, Budapest, Hungary. Hungarian Meteorological Service: 62-82.

Deser C. 2000. On the teleconnectivity of the "Arctic Oscillation". Geophysical Research Letters 27: 779-782.

Environment Canada. 1976. Internal memorandum no. OBS 2-76, Atmospheric Environment Service, Downsview, Ontario, Canada, November.

Godson WL. 1955. Report on Canadian standard barometry, Atmospheric Environment Service, Toronto, Ontario, Canada.

Hurrell JW. 1995. Decadal trends in the North Atlantic oscillation: regional temperatures and precipitation. Science 269: 676-679.

Itoh H. 2002. True versus apparent Arctic oscillation. Geophysical Research Letters 29: 1268. DOI: 10.1029/2001GL013978

Jones PD. 1987. The early twentieth century Arctic high - fact or fiction? Climate Dynamics 1: 63-75.

Jones PD, Jónsson T, Wheeler D. 1997. Extension to the North Atlantic oscillation using early instrumental pressure observations from Gibraltar and south-west Iceland. International Journal of Climatology 17: 1433-1450.

Jones PD, Davies TD, Lister DH, Slonosky V, Jönsson T, Bärring L, Jönsson P, Maheras P, Kolyva-Machera F, Barriendos M, MartinVide J, Alcoforado MJ, Wanner H, Pfister C, Schuepbach E, Kaas E, Schmith T, Jacobeit J, Beck C. 1999a. Monthly mean pressure reconstructions for Europe. International Journal of Climatology 19: 347-364.

Jones PD, Salinger MJ, Mullan AB. 1999b. Extratropical circulation indices in the Southern Hemisphere based on station data. International Journal of Climatology 19: 1301-1317.

Kaplan A, Kushnir Y, Cane MA. 2000. Reduced space optimal interpolation of historical marine sea level pressure: 1854-1992. Journal of Climate 13: 2987-3002.

McMaster RS. 1975. Memorandum No. 8437-1 from ACNS to ACNC. Data Standards Division, Government of Canada, Toronto, Canada, 22 September.

Middleton WEK. 1964. The History of the Barometer. Johns Hopkins University Press: Baltimore. 
Mo KC, Livezey RE. 1986. Tropical-extratropical geopotential height teleconnections during the Northern Hemisphere winter. Monthly Weather Review 114: 2488-2515.

Moberg A, Bergström H, Ruiz Krigsman J, Svanered O. 2002. Daily air temperature and pressure series for Stockholm (1756-1998). Climatic Change 53: 171-212.

New M, Hulme M, Jones PD. 2000. Representing twentieth century space-time climate variability. Part 2: development of 1901-96 monthly grids of terrestrial surface climate. Journal of Climate 13: 2217-2238.

Nicholls N. 2001. The insignificance of significance testing. Bulletin of the American Meteorological Society 81: $981-986$.

Nkemdirim LC, Budikova D. 2001. Trends in sea level pressure across western Canada. Journal of Geophysical Research D 106I: $11801-11812$.

Peterson TC, Easterling DR, Karl TR, Groisman P, Nicholls N, Plummer N, Torok S, Auer I, Boehm R, Gullett D, Vincent LA, Heino R, Tuomenvirta H, Mestre O, Szentimrey T, Salinger J, Førland E, Hanssen-Bauer I, Alexandersson H, Jones PD, Parker DE. 1998. Homogeneity adjustments of in situ atmospheric climate data: a review. International Journal of Climatology 18: $1493-1517$.

Potter JG. 1955. Monthly mean sea level pressure maps for Canada. CIR-2710, Tec-224, Meteorological Division, Department of Transport: Toronto, Canada, 18 October. 1955.

Rogers JC, McHugh MJ. 2002. On the separability of the North Atlantic oscillation and Arctic oscillation. Climate Dynamics 19: 599-608.

Savdie I. 1982. AES barometry program, Technical Record No. 9. Network Planning and Standards Division, Data Acquisition Services Branch, Environment Canada, Downsview, Ontario, Canada, August.

Shabbar A, Higuichi K, Skinner W, Knox JL. 1997. The association between the BWA index and winter surface temperature variability over eastern Canada and west Greenland. International Journal of Climatology 17: 1195-1210.

Slonosky VC. 2003. The meteorological observations of Jean-François Gaultier, Québec, Canada 1742-56. Journal of Climate 16: $2232-2247$.

Slonosky VC, Yiou P. 2001. The North Atlantic oscillation and its relationship with near surface temperature. Geophysical Research Letters 28: $807-810$.

Slonosky VC, Jones PD, Davies TD. 1999. Homogenization techniques for European monthly surface pressure series. Journal of Climate 12: $2658-2672$.

Stephenson DB, Pavan V, Bojariu R. 2000. Is the North Atlantic oscillation a random walk? International Journal of Climatology 20: $1-18$.

Thompson DWJ, Wallace JM. 1998. The Arctic oscillation signature in the wintertime geopotential height and temperature fields. Geophysical Research Letters 25: 1297-1300.

Upton FT. 1972. Headquarters standards and procedures for barometry in Canada. Atmospheric Environment Service, Toronto, Canada.

Van Loon H, Rogers JC. 1978. The seesaw in winter temperatures between Greenland and northern Europe. Part 1: general description. Monthly Weather Review 106: 296-310.

Vincent LA, Zhang X, Bonsal BR, Hogg WD. 2002. Homogenization of daily temperatures over Canada. Journal of Climate 15 $1322-1334$

Walker GT, Bliss EW. 1932. World weather V. Memoirs of the Royal Meteorological Society 4: 53-84.

Wallace JM, Gutzler DS. 1981. Teleconnections in the geopotential height field during the Northern Hemisphere winter. Monthly Weather Review 109: 784-812.

Wanner H, Brönnimann S, Casty C, Gyalistras D, Luterbacher J, Schmutz C, Stephenson DB, Xoplaki E. 2001. North Atlantic oscillation - concept and studies. Surveys in Geophysics 22: 321-382.

Young KC. 1993. Detecting and removing inhomogeneities from long-term sea level pressure time series. Journal of Climate 6: 1205-1220.

Zhang X, Vincent LA, Hogg WD, Niitsoo A. 2000. Temperature and precipitation trends in Canada during the 20th century. Atmosphere-Ocean 38: 395-429. 